few years the fishery has suffered greatly and it is now virtually abandoned. (3) In 1930 (and though exact figures are not available it was evidently much the same in former years) the offshore plankton contained Sagitta elegans, which is characteristic of mixed Atlantic water, and S. setosa, which is characteristic of Channel water, in the proportions of $94: 6$; but since 1932, with a single exception in 1936, these proportions have been reversed. (4) The winter maximum of dissolved phosphate has over the same period shown a heavy decrease, amounting on the average to about 35 per cent. Comparable data from other areas are not available, but the failure in recent years of the Donegal herring fishery has been accompanied by a similar change in the constitution of the shoals and may be due to the same causes.

The changes in the Plymouth area are due, it seems, to the lack of influxes of phosphate-rich water from the Atlantic. Salinity and temperature records show, indeed, that incursions of Atlantic water have passed up the Channel ; but the records cannot be correlated with the biological and phosphate data, and the great influx of Atlantic water into the North Sea in 1921 is known to have been detrimental to the herring fisheries. It thus appears that influxes may be of more than one kind, and that only water rich in phosphate, or potentially rich because it carries an abundant plankton, will benefit the Channel fauna.

The second illustration of a long-period fluctuation is from northern waters. Here there have recently been great changes in the fauna, owing to a rise of $1^{\circ}$ or $2^{\circ} \mathrm{C}$. in the temperature of the water, and this is due, presumably, to an increase in the strength of the Atlantic drift. By reason of this change, many animals have been able to extend the limits of their distribution and in almost every section of the fauna significant movements have been noted; profitable cod fisheries have been established at Bear Island and in West Greenland, and an unusual abundance of herring has been found on the Murman coast.

Long-period fluctuations are thus due to a widespread alteration in some hydrographic factor in the environment and though, in the two instances given, this factor is different-at Plymouth phosphate and in northern waters temperature-it is in the ocean to the west that the changes originate and it is here, in the open Atlantic, that the reasons must be sought. At present our knowledge of the circulation in the North Atlantic is very deficient, but with the work now in progress it is to be expected that the main features will shortly be better known. To the biologist, however, it is the irregularities in the system which are of primary importance, and it is only by regular and repeated observations carried out over a wide area that the causes of these long-period fluctuations can be discovered.

In conclusion, attention is directed to the need for greater activity in fishery administration throughout the Empire, for though there are some notable exceptions, it appears that the lessons we have learnt in Great Britain are not generally understood elsewhere. In almost every problem in marine biology it is essential to possess a background of fundamental knowledge, which can only be obtained by long years of patient study. In many parts of the Empire not even a beginning has been made in the acquisition of such knowledge; there are vast areas in which no single species of fish can as yet be recognized in all its stages of development, while little or nothing is known of such matters as rate of growth, spawning periods, food, migrations and fluctuations in abundance. The importance of such information cannot be over-estimated, for the opportunity of dealing effectively with a fishery problem will almost invariably be lost unless knowledge has been obtained in advance and is ready for application.

\section{Correlations and Culture: A Study in Technique}

DROF. GRIFFITH TAYLOR'S presidential address to Section E (Geography) falls into three divisions. In the first the field of cultural geography is considered, in the second a technique which has been found invaluable in that subject is discussed and illustrated ; finally, suggestions are made as to the aspects of culture which should be included in a general education. The relation of geography to history, anthropology, sociology and philology is emphasized. It is shown that there are common fields of research in which the technique of the 'physical' scientist can be used by the cultural geographer to aid in problems in the 'humanistic' disciplines.

The aid geographers can give to historians is illustrated by examples from the Weald and from the blue-grass country of Kentucky. The characteristic cultural development in both is shown to depend on structure primarily, though most historians ignore this important correlation. The use of isopleths (lines of equal abundance) can be used with profit in an interpretation of the essential features of the Renaissance. As an indicator of trends and salient features, they might well be more extensively used by the historian.

The geographer's task should be to teach the student to doubt dogmas involving distribution, and to make his own deductions from fundamental data. In a general education this is a far more valuable function than memorizing economic data, which fills so much of geographic teaching to-day. 
One of the main purposes of the address is to show that from the map of the distribution of culture-facts, the investigator can deduce the cradle of the various cultures and the order of their evolution. This principle, long used by the botanist and biologist, is of great value to the anthropologist, sociologist and philologist. The distributions of man, of various industries and populations, of languages, etc., belong to the field of the geographer. A lengthy study of such distributions leads to views often much at variance with those accepted as orthodox. Some examples discussed are the cradle-land of man, the differentiation of the races, the inaccuracy of the terms 'Caucasian' and 'Mongolian', the spread of cultures from Asia into the Pacific, and the probable cradle of civilization. In many of these problems the implications of the isopleths have been ignored by most researchers.

It is suggested that a new term is needed for groups which are linked by culture, but are not racial units. An extension of the use of the word 'cult' is suggested. Thus there is no Jewish race in Europe, or French race in Canada; but it is logical to talk of a Jewish or French 'cult'. Race should denote 'breed', and is purely a biological concept. The problem of the Jews and of the Aryans is used to illustrate a glaring example of dangerous ignorance on the part of powerful political groups. A new technique of approaching linguistic relationships-based on distributions-is discussed. It seems to offer clues as to the relationships between, and the origins of, Aryan, Basque, Altaic, and other linguistic groups. Prof. Griffith Taylor believes that the Aryan languages originated near the Caspian. He suggests that the isopleths support the view that the Nordic race originally spoke Finn or some allied nonAryan language.

Geographers may be classified in three groups: theocratic (that is, teleological), environmental or possibilist. A belief in environmental control, to which the name "Stop-and-go Determinism" has been given, is favoured. It is opposed to the orthodox views of geographic philosophy.

A drastic revision of the programme for a general cultural education is required, especially in the Dominions. Educators must abandon the technique of Augustine of Canterbury for that of Aristotle. The latter tried (in a living language) to put the youth of Greece en rapport with the vital problems of the day. He did not insist on their spending years trying to learn the long-dead language of Tutankhamen.

It would seem desirable to swing the attention of youth for a generation or two from a study of classics or of the problems of physical science to the more difficult and dangerous problems of social science. There is no risk to-day, though there was in the past, in stating that the earth is a globe, revolves around the sun, and is of infinitely small importance in the cosmos. But there is grave danger in many circles in stating the truth about Communism, Socialism, Judaism, Nordicism, and many other -isms which conflict with established or dictatorial interests. These creeds are cultural facts, which can be more readily understood if tackled in a graphic manner. It is no quibble to say that they are to-day more vital to the man of culture, that is, with a wellrounded education, than is the well-recognized and valuable culture based on art, music, or classics. Thus the geographer whose interests lie not only in the economic but also in the cultural field can feel that he is working right on the battlefront in man's progress towards a higher type of civilization.

Eighteen ecological diagrams form an essential feature of the address.

\section{Scope and Method of Economics}

$7 \mathrm{HE}$ object of the presidential address by Mr. R. F. Harrod to Section F (Economics) on method is threefold : (1) An attempt is made to show the kind of knowledge on which the practical recommendations, which economists have been in the habit of giving with a considerable degree of assurance, are grounded. (2) An attempt is made to define precisely the empirical basis of the general laws which constitute traditional economic theory. (3) Attention is given to the new ground over which contemporary theory, more tentative and more empirical, is striving to advance.

The recommendations do not issue from a set of 'laws' relating to the causal sequence of events. The scientific groundwork of these recommendations is a systematic classification of different kinds of economic activity and a simultaneous conspectus of the system as a whole. For example, the condemnation of protection is not based on precise knowledge of the sum of consequences likely to result from it; but when we have made a systematic classification of the purposes of economic effort and grasped the mode of operation of the system of a whole, we see that protection fails to take account of this, implicitly assumes a different working of the system and, save in exceptional circumstances, produces a net residue of frustation.

The economist's criterion of the good as that which is preferred is defined, and it is shown that it may be validly employed whatever the moral or political objectives of the society may be. The economist's criterion is free from 